\title{
Can overseas migrants develop sustained entrepreneurship? Multiple case studies of Wenzhou migrants in Italy
}

Yili Zhang ${ }^{*}$ and Min Zhang

\author{
*Correspondence: yili66@163.com \\ Business School, Research Center of \\ Wenzhounese Economy, Wenzhou \\ University, Chashan University \\ Town, Wenzhou, Zhejiang Province \\ P.R.325035, China
}

\begin{abstract}
This study focuses on Wenzhou migrants and explains the developmental path of overseas migrants' sustained entrepreneurship. It also analyzes how migrant entrepreneurs fit into the Italian culture to improve ambidextrous innovation ability. This paper applies the methods of induction and longitudinal study, conducts case studies on four migrant entrepreneurs, and explores embedding strategies in different developmental stages of entrepreneurship. Our analysis reveals that Wenzhou migrants' enterprises are able to develop interactive fusion with the Italian culture. The embedded culture also plays different roles in motivating innovation at different stages of entrepreneurship. The types of connections between the Wenzhou migrants' cluster network and their embedded culture in the regional economy evolves as the stages of entrepreneurship change. These results enrich existing theories and offer valuable insights into the study of overseas migrants' sustained entrepreneurship.
\end{abstract}

Keywords: Migrant entrepreneurs, Embedded network, Embedded culture, Sustained entrepreneurship, Ambidextrous innovation

\section{Background}

The multipolarization of the world economy that led to a large number of migrations also accelerated integration of Chinese overseas immigrants into a wide range of regional economic development. Chinese immigrants are combining their social capital and local innovation factors to create significant wealth for individuals, families, cluster networks, and even local economic development. This population plays an important role in the process of building an open, inclusive process of balanced regional economic cooperation. There are nearly 600,000 immigrants from Wenzhou in more than 130 countries and regions around the globe. This is a group of "familiar strangers"; "familiar" means that their credits and operating conditions are well known to the group's members. A shared language and shared values also mean that capital can be effectively aggregated and increase in value. Full trust among individuals allows critical information to be quickly and inexpensively transmitted between network nodes. "Strangers" means that the individuals are unfamiliar with the regional economic, cultural, and other information outside of the group. They have contact with the outside community only through economic exchanges, and lack social and cultural exchanges. The increasingly refined industrial chain collaboration makes Wenzhou immigrants

(c) Zhang and Zhang. 2016 Open Access This article is distributed under the terms of the Creative Commons Attribution 4.0 International License (http://creativecommons.org/licenses/by/4.0/), which permits unrestricted use, distribution, and reproduction in any medium, provided you give appropriate credit to the original author(s) and the source, provide a link to the Creative Commons license, and indicate if changes were made. 
form a more-closed social network. The Wenzhou dialect became the prevailing language used. Barriers to accessing information make it difficult for Wenzhou immigrants to integrate into the local society. However, through this group's efforts the individual social capital in this community of shared values and trust quickly solidified and become an embedded network (Chen and Zhang 2013), and smoothly developed to maturity. Due to the uncertain external environment, overseas start-ups need continuous stimulation from potential entrepreneurs. Network and social capital, innovation, values, and other factors become critical variables that affect ongoing entrepreneurship (Steier 2001).

Sustained entrepreneurship entails continuing to break the existing internal organizational and external institutional constraints. Using new knowledge and obtaining abilities to implement a series of strategic business behaviors all need the help of continuous system innovation and cultural innovation to keep immigrant entrepreneurship going (Li et al. 2008). Since sustained entrepreneurship is an integration of entrepreneurs, families, businesses, products, industry, and other elements, sustainable business itself is an important part of the entrepreneurial process (Hoy and Sharma 2010). What guidance is most useful to this group during the initial startup phase and the sustaining phase? How can immigrant groups be integrated into the regional economy and regional culture? How can network resources be effectively embedded in external information? Solving these problems has important theoretical and practical significance for the right to speak, and to promote sustainable growth cluster networks for overseas immigrants.

In recent years scholars have shown great interest in ambidextrous innovation. They believe the strategy that takes both exploratory innovation and exploitation innovation into account is an important means to enhance innovative capabilities (Lakemond and Detterfelt 2013). Achieving ambidextrous innovation becomes a business strategy for immigrant entrepreneurship. Since embeddedness is a basic characteristic of the development of cluster networks, exploring the mechanism of ambidextrous innovation from the perspective of embeddedness is a feasible reference for Wenzhou immigrants to sustain entrepreneurship. However, these "familiar strangers" face both restrictions from traditional embedded practices and the need to properly deal with external complex social networks. Developing a specific environment that matches the embedded strategy and thus promotes ambidextrous innovation will be critical to immigrants' entrepreneurship sustainability. However, despite the growing scope of research on embeddedness, there is a lack of collaborative study on the different dimensions of embeddedness. Even some studies that associate network embeddedness with innovation performance fail to factor in cultural, institutional, and other network environments in which individuals are situated in the analytical framework. Research on the association between embeddedness of cluster networks constructed by immigrants and ambidextrous innovation is particularly lacking. The existing research cannot provide interpretations of the path to a viable ongoing business by overseas immigrants. In view of this, this study focuses on the network development of Wenzhou immigrants in Italy, starting with industrial life cycle theory, embedded network theory, and ambidextrous innovation theory, then exploring the impact of different forms of embeddedness on ambidextrous innovation at various stages of entrepreneurship. This study uses exploratory analysis of multiple case studies to address the following questions: whether 
changes in the external environment will have an impact on the extent of relationship embeddedness in the cluster networks of Wenzhou immigrants; whether an interactive integration of Wenzhou business and regional Italian culture can be achieved, and whether this cultural embeddedness is conducive to ambidextrous innovation; and whether a coupling relation exists between relationship embeddedness within the network and cultural embeddedness in the regional economy. In-depth insights into the above questions can help select and shape sources of embedded advantages consistent with the external environment and internal competitive advantage, helping immigrants to obtain core competitiveness for sustaining entrepreneurship.

\section{Theoretical framework}

\section{Development of immigrant entrepreneurship and cluster networks}

The rapid development of globalization makes possible increasingly frequent cross-border migration. In order to avoid employment barriers, many immigrants give up opportunities in the labor market and decide to start their own business. Immigrant entrepreneurship has become an important factor in promoting social and economic development in many Western countries. Western scholars have studied the phenomenon of immigrant entrepreneurship and achieved fruitful results, while research in China has just begun (Chen and $\mathrm{He} 2010$ ). Scholars believe that disadvantages in the labor market and the unique resources of immigrant groups are the main factors driving immigrant entrepreneurship. Establishing, maintaining, and developing social relationships within the ethnic groups of immigrants is more important than accepting formal education and integrating into the mainstream society of the relocated country (Wang 2012). Further, one study finds that idiosyncratic resources in terms of endowments and social identity of immigrant entrepreneurs determine their various paths to entrepreneurship (Ndofor and Priem 2011). However, scholars have doubts about the long-term performance of immigrant entrepreneurship because the traditional industries those immigrants mainly engage in lack sustaining growth. Although internal networks of immigrants can gather the resources needed to start a business, they cannot provide the power required for continuous growth (Chaganti and Greene 2002). Sustainable immigrant business depends directly on the degree of fit between resources and the entrepreneurial path chosen, and previous literature rarely includes strategies on how to achieve such fit.

Resources within immigrant groups not only promote immigrant entrepreneurship, but can also directly promote the formation of the industrial chain, and eventually generate clusters. The competitive advantage of clusters comes from the nature of its network. In the formation and development stage of cluster networks, the interdependence of organizations with the cluster accelerates resource gathering, and promotes sharing of knowledge and continuous accumulation of technology. Once it has entered the mature stage, such roots can cause stagnation, and innovation inertia becomes a barrier to the transformation and upgrading of industrial clusters. In the current conditions of Wenzhou immigrants, individual qualities, interrelation of network nodes, network openness, and interaction with other entrepreneurs' networks are still far from being able to adapt to the requirements of economic restructuring and development (Zhang et al. 2012). Although clusters generally experience the process from birth to recession, in their entire life cycle theoretical issues such as exactly what factors drive the evolution of cluster networks and the formation of a particular evolutionary path 
have yet to be explored. Despite the recent emergence of a number of theoretical and empirical research works on the life cycle of regional industrial clusters and regional economic development, relevant research on how to prevent immigrant cluster networks from prematurely entering a locked state and how to use the sustaining entrepreneurship of immigrant businesses to promote the organizational evolution of cluster networks is still very rare.

Prior literature suggests that sustaining entrepreneurship is both the source of the continued competitiveness of business and the basis for the evolution of cluster networks in achieving self-organization (Etemad 2004). Achieving sustained entrepreneurship requires both upgrading of products or services to meet the market demand, and constantly adapting to the external environment. Sustaining an immigrant business is closely related to the innovation capability of the business; sustained entrepreneurship further promotes the embedding behavior of cluster networks. The investigation of the relationship between innovation performance and embeddedness of cluster networks has been a focus of recent academic research. Sustained entrepreneurship of immigrants and the evolution of self-organization of cluster networks have consistent internal development logic. The success of sustained entrepreneurship relies on the cluster network, and a clustered business must rely on innovation to succeed in a competitive environment, and achieve escalation and development through innovation (Ji et al. 2011). However, some scholars believe that getting away from its original roots as soon as it enters a mature stage is more conducive to a cluster network's structural adjustment and optimization and upgrading. Questions such as which forms are able to maintain a network that balances open and closed embeddedness, and how opportunities to implement a dynamic embedding policy can be found have not yet been addressed. Although companies can react to changes in the external environment by changing the relationship between organizations to achieve a dynamic fit between network embeddedness and the environment (Ndofor and Priem 2011), few studies have explored to what extent the environment impacts the cooperative behaviors of immigrant businesses within the cluster network, and how sensitive these effects are.

\section{Relationship between embeddedness and ambidextrous innovation}

Ambidextrous innovation is a major focus in recent studies on innovation. Researchers believe that exploration and exploitation are two distinct ways of thinking; both fight for the organization's scarce resources, but the organization cannot supply both (Lavie et al. 2010). Emerging views claim that cross-border ambidextrousness and timesequence planning can effectively resolve resource conflicts (Russo and Vurro 2010). Exploring how to balance the relationship between exploratory innovation and exploitative innovation, and the implementation mechanism inherent in ambidextrous innovation have become cutting-edge issues in current Western research.

With cluster networks evolving to a higher level, connections among organizations not only generate advantages of growth and innovation but also lead to disadvantages of inertia and stagnation (Hulsink and Elfring 2008). Wenzhou's unique regional culture offers a regional immigrant temperament of daring to disobey, being willing to take on challenges, skilled at doing business as a group, as well as being too risky, utilitarian, pompous, and narcissistic, among other unique regional characteristics (Xu 2012). Wenzhou immigrants in Italy use "guanxi" as their basis. Guanxi determines that the 
network's expansion is based on a closed network, and it defines the extent of closeness of ties, the content of relationships, and relationship quality between members. Thus we use relationship embeddedness as a main dimension to measure social capital. Research on embedded relationships is generally interorganizational or intercluster. The embedding process is accompanied by a complex heterogeneous knowledge acquisition process, and impacts individual innovation behavior (Tang and Zou 2012). Granovetter believes that embeddedness in the network can be used to measure the degree to which individuals attend to the needs and goals of others, levels of trust, and the degree of information sharing (Granovetter 1985). Strong- and weak-tie theory also recognizes the important roles that trust and information sharing play in the process of relationship embeddedness. Although information sharing is conducive to dissemination of innovative ideas, too much sharing of information can result in information redundancy and curb innovation. Heterogeneous information from a broader range is more helpful for individuals in innovating (Baer 2010), therefore more researchers believe that weak ties promote innovation. However, some scholars believe that this promotion is established only within a certain range. A U-shaped relationship exists between information sharing and increase in individual performance. Too much information can lead to information fragmentation. The inability to effectively identify innovative information can lead to a decline in individual creativity (Perry-Smith 2006).

Recent research further refines the types of innovation. Empirical studies have shown that strong ties are more conducive to exploitative innovation, while weak ties help explorative innovation. Individuals benefit from social capital at the expense of limiting freedom of decision (Moore et al. 2009). However, these studies treat strong and weak ties as independent antecedent variables in order to explore their association with innovation performance. Although some studies take into account the density of the network structure, they still fail to organize the organizations within a cluster and the embeddedness of the network environment in the analytical framework, which may be the cause of many inconsistent findings.

\section{Cultural embeddedness and ambidextrous innovation}

Economic behaviors can be embedded in social networks and the institution, as well as the cultural environment (Granovetter 1985). Culture and political forces have an unavoidable impact on individual behavior and network characteristics, and thus research has gradually incorporated cognitive embeddedness, cultural embeddedness, and institutional embeddedness into the analytical framework of embeddedness theory. Culture emerges in forms such as collective beliefs, values, practices, philosophy, and lifestyle. It establishes the limits of economic rationality and shapes practices within the organization because shared values across a culture link humanity and empathy. The important impact of shared beliefs and values on participants' behavior is called cultural embeddedness (James 2003). Chinese scholars generally define cultural embeddedness as the values and norms of behavior shared by the whole cluster network (Xiang 2013). Access to and utilization of network resources inside and outside of the cluster enterprise depends on the differences in their competitive advantage, and access to and utilization of network resources are the result of the corporate initiative of constructing networks. The process and willingness to construct networks are ultimately influenced by regional culture. Cultural embeddedness thus impacts network resources 
and utilization levels through network behaviors of clustered enterprises, thereby resulting in differences in innovation levels, and directly determines the course of evolution of the cluster network.

Innovation is a social, regional interactive process. Tacit knowledge is manifested in the form of technology and skills generated by enterprises embedded in the local culture. Various content and dimensions of cultural embeddedness encourage or restrict different types of innovation behaviors (Boschma 2005). On the one hand, proximity of networks helps to promote cluster network enterprises in establishing partnerships with others. While establishing trust and peripheral businesses, they can access key informational resources together to solve problems. On the other hand, spatial and cultural proximity have a complementary relationship, conducive to the formation of a dense resource of networks (Hsu and Saxenian 2000). Social and cultural proximity help build trust between enterprises, reduce opportunistic behavior, and increase sensitivity to external information (James 2003). Cluster companies have to keep up with entrepreneurship and innovation in order to elevate the cluster networks to a high or multi level, and evolve to self-organizing. A constantly improving and ordered competitive market, sufficient market governance, and social and cultural networks conducive to entrepreneurship are the external conditions for entrepreneurship and sustaining growth.

\section{Methods}

From prior literature we know that sustained entrepreneurship is an important stage of the entrepreneurial process. Achieving sustained entrepreneurship requires entrepreneurs' special talents such as knowledge, experience, or values to implement the strategy update, and the integration of existing resources and embeddedness (Sarasvathy and Dew 2005). A large number of overseas migrants constantly move between laborintensive industries with low entry bars because of the shortage of resources and the pursuit of rapid growth. Huge market opportunities and transitional costs simultaneously prompt immigrants to change cities for quick profits. The start-up phase and sustaining phase of overseas immigrant businesses not only need to take full advantage of the internal network of social capital, but are also inevitably affected by local culture, social relations, and the like. The evolution of cluster networks established by immigrants needs moderate heterogeneity, but must also integrate localized learning (Maskell 2010).

Since the function of network structure depends on different scenarios, relational capital within the cluster network is also affected by regional social and cultural factors (Boschma 2005). To reveal the mechanism of sustained entrepreneurship in cluster networks, it makes sense to utilize the relational embeddedness within network boundaries and cultural embeddedness outside of the network. In summary, this study explores the mechanism behind the influence of cultural embeddedness and relational embeddedness during the start-up phase and sustaining phase of overseas immigrant businesses on enterprises' ambidextrous innovation behaviors; and the interactive pattern and cooperative path that occur when individuals within the social network maintain internal social capital while seeking outside social capital (see Fig. 1).

Case studies can profoundly analyze and theorize the emerging phenomena and problems during management practice (Yin 2008). This study uses the case study method for the following reasons. First, this study focuses on how immigrant 


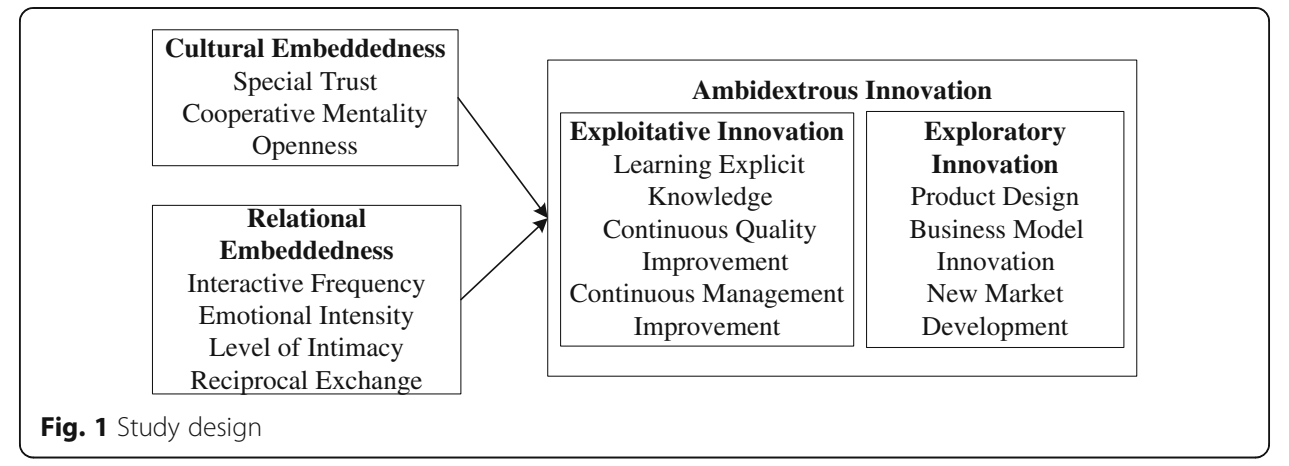

enterprises embedded in cluster networks interact and integrate with the regional Italian culture at different stages in order to improve their ability to achieve sustained entrepreneurship. By exploring the hidden mechanism behind this complex phenomena, case studies can clearly display the vivid and detailed logical association found and thus provide a clear answer on this question. Second, this study looks at the innovation bottleneck and ways to resolve it during immigrant cluster network development. Case studies have demonstrated superiority in studying dynamic processes, making it possible to explain variations in the processes. The object of the study is immigrant entrepreneurial behavior in enterprises, and entrepreneurs directly determine the company's innovative orientation and entrepreneurial path. In this article we use embedded behaviors and innovative behaviors of immigrant entrepreneurs to measure the embeddedness and ambidextrousness of immigrant businesses. In order to draw common conclusions from the repeated induction process, the present study uses an inductive, multiple case study design, applying replication logic to cross-validate propositions obtained from different cases in order to obtain more robust and pervasive theories (Eisenhardt and Graebner 2007).

\section{Case selection and case description}

This study uses the following criteria for case selection: First, in order for the external environment to remain relatively consistent across cases, selected cases are all companies established by Wenzhou immigrants in Italy that had been in business for over ten years. All had experienced the start-up and sustained entrepreneurship stages; tried different industries or different cities; and sustained entrepreneurship by promoting their business, resulting in better performance and development prospects in the industry in which they currently worked. Second, in the business development process these companies made use of the relational resources within the network to varying degrees, and established relationships with stakeholders in Italy. Third, the selected entrepreneurs possess certain abilities to innovate but present differences in the degree of integration and embedding of innovative resources of the network. This helps the comparative analysis explore the impact of internal motivation and ability to innovate on mechanisms leading to differences in innovation, thereby strengthening the rigor and generalizability of the research findings (Eisenhardt and Graebner 2007). Fourth, the selected entrepreneurs can provide rather-detailed information for obtaining the information necessary for case studies. In compliance with the above criteria, this study chose 
four entrepreneurs, represented by the names $\mathrm{H}, \mathrm{ZR}, \mathrm{X}$ and $\mathrm{ZY}$; they are involved in four different industries-furniture, clothing, footwear, and bags. These four industries employ the most immigrants from Wenzhou and are representative of the general immigrant industry in Italy. The cluster network of immigrant businesses has grown from start-up to maturity. In addition, due to the low educational level of Chinese migrants in Europe overall, nonelite immigrants are still the major component of Wenzhou migrants in Italy (Song 2013; Zhou and Zhu 2014). This study selected four cases in which the entrepreneurs have a middle-school education and belong to the nonelite group. Thus conclusions of the cases have strong reliability and construct validity, providing some guidance for other immigrant businesses. See Table 1 for basic information on the cases.

Table 1 Basic information on cases

\begin{tabular}{|c|c|c|}
\hline Case number & Industry & Case description \\
\hline Entrepreneur $\mathrm{H}$ & Furniture & $\begin{array}{l}\text { In } 2001 \mathrm{H} \text { followed a cousin to Italy. Two years later, } \mathrm{H} \text { helped his younger } \\
\text { brother and sister apply to Italy. } \mathrm{H} \text { first worked for her mother's cousin; the } \\
\text { family then got together to make sofas. In } 2005 \mathrm{H} \text { went to Prato to help in } \\
\text { his younger brother's timber frame factory, run by a partnership of the three } \\
\text { siblings. The younger brother and sister were in charge of making sofas. } \\
\mathrm{H} \text { knew some Italian and went out to produce contracts for business. In June } \\
\text { 2006, in partnership with his sister, } \mathrm{H} \text {. invested more than } 800 \text { thousand Euro } \\
\text { into a start-up sofa factory in Montermurlo, a town under the jurisdiction of } \\
\text { Prato. The three siblings separated in } 2010 ; \mathrm{H} \text { now owns the sofa factory } \\
\text { independently. Today H has more than } 20 \text { workers and is the original equipment } \\
\text { manufacturer (OEM) for two of the largest sofa companies in Prato. }\end{array}$ \\
\hline
\end{tabular}

Entrepreneur ZR Garment Before ZR came to Italy, she was a substitute teacher and police clerk. In the first two years ZR worked at a restaurant in Milan, earning 2,000 ITL a month, equivalent to 66 USD. In addition to working at the restaurant ZR also made purses and supplied bean sprouts to all Chinese restaurants in Milan. ZR learned some basic Italian when working in the restaurant. In early 1989, ZR opened a restaurant in Follmeo using her savings, and then gave birth to three children. ZR brought her mother and siblings from China to Italy and was in debt. In 1993 ZR came to Prato to start an OEM for clothes, learning garment production and company management from scratch. Six months later ZR repaid all of her debt, and within a year her entire life conditions had changed. In 2008 ZR began operating her own clothing company, expanding from one worker to over 30. The company now has four Italian employees, and the average monthly income amounts to 1 million EUR. In addition to clothing, ZR also owns a restaurant. ZR currently devotes herself to the clothing business and handed over care of the restaurant to a friend.

Entrepreneur X Footwear $\quad X$ had no work experience before immigrating to Italy. $X$ went to Shanghai for two years to study French and English. At the end of $2000 \mathrm{X}$ went to study in Switzerland. In $2002 X$ entered France illegally and made clothes for Wenzhou businessmen in a basement. In 2004 she met her boyfriend in the factory and married. Soon after, she took refuge with her husband's relatives in Italy and received more than 10,000 EUR as a wedding gift. X spent 30,000 EUR to buy an import export and wholesale business in a mall in Naples. In 2009 X obtained the right to reside in Italy through amnesty; she now imports over 10 containers per year. Her customers come mainly from Italy and other countries in Europe. $X$ is ready for expansion and plans to soon buy another store in Naples' Chinatown.

Entrepreneur ZY Luggage and ZY's father migrated to Italy in the early 1980s. In 1988 ZY, together with his bags brother and mother, came to Italy. After graduating from middle school, ZY first worked in Florence in a luggage factory. After accumulating some work experience, $Z Y$ and his brother went to Venice and worked in the wholesale bag industry. In 1994 they returned to Florence to join a joint venture in Italian leather goods with friends. They established direct contact with brand companies as the OEM of high-end brands. In 1997 they became the OEM for Chanel. In 2006 ZY began work as an agent for middle-range wines. By 2009 ZY, along with friends, had become the top Italian wine distributor in China. ZY established a Shanghai wine company in 2010. In 2005 ZY was elected as a foreign congressman of Florence. 


\section{Data collection}

Data collection methods in this study include in-depth interviews, archival records, and onsite verification, using a wide range of data sources to achieve mutually complementary and cross-validation of data (Yin 2008) in order to improve the validity of the cases. The researchers made two trips to University of Florence in Italy for short-term academic exchanges in 2011 and 2013. As visiting scholars at the University of Florence from March to July 2014, we conducted in-depth research on Wenzhou immigrant entrepreneurs in Italy. We also established various types of contacts with commerce groups established by Wenzhou overseas immigrants. Channels of communication were established by way of snowballing, including the head of the Chamber of Commerce, supply chain member companies, and related businesses. The study was conducted mainly through face-to-face interviews. In addition, internal information from the overseas Wenzhou Chamber of Commerce, Chinese business newspapers, and online media information were additional sources of data. In addition to formal interviews, this study also used forms of informal conversations for more information and insights, such as participation in meetings held by the Chamber of Commerce, visiting Chinatown and stores, and traveling and dining with Wenzhou immigrant entrepreneurs in order to determine the true feelings of overseas Wenzhou migrants and their living and working environment, production and business philosophy, social life, and cultural integration. We also collected background information through policy documents and academic literature to continuously adjust interview outlines and verify the authenticity of the respondents' answers. The raw data was then coded, and went through the initial extraction and construction of the theoretical concepts. Information on the theory continued to be collected, using multiple sources of evidence of triangulatory verification.

\section{Data analysis and coding}

Based on previous general extraction procedures of qualitative data, we set up the framework model with a bottom-up approach (Miles and Huberman 2008), constructed the underlying theoretical structure from data coding, and gradually explored the relationship between concepts. The main innovative activities carried out in the start-up and during sustained entrepreneurship were studied from the longitudinal studies of a single case, and on the basis of identifying the different stages of exploratory innovation and the pattern of changes in exploitative innovation to conduct cross-case analysis. Finally, the overall theoretical framework was formed.

This study combines theory from existing literature (Hofstede et al. 1991; James 2003) on the basis of an initial scope of category and refined to obtain the following subcategory. "Cooperative mentality" refers to the sense of active cooperation with local businesses that continues to maintain business contacts; "special trust" implies a feeling of trust-based identity but also a feeling of trust for the locals, as reflected in the tendency to strengthen cooperation and exchanges with local businesses and employees. Since the network not only provides resources but can also be a restraint and control, the biggest obstacle between the cluster network of the Wenzhou immigrant population and the outside world is language. Business emphasizes the openness of enterprises, which signifies that language is a necessary condition for expanding resources to the outside. Interaction frequency, emotional intensity, degree of closeness, and mutual exchange are taken from Granovetter's classic literature (2007), which has strong 
theoretical validity. Exploratory innovation includes search, change, risk taking, and other behaviors; exploitative innovation includes optimization, efficiency, selection, implementation, and similar behaviors. Drawing on previous research results, we categorize learning explicit knowledge, continuous quality improvement, and management of continuous improvement in access to and utilization of resources, and categorize product design, business model innovation, and new market development into the integration and recycling of resources (Benner and Tushman 2003).

Finally, by further exploring the relationship and logical order between different concepts, we highlight the main concepts of cultural embeddedness, relational embeddedness, exploitative innovation, and exploratory innovation. Among them, cultural embeddedness contains special trust, cooperative awareness, and degree of openness; relational embeddedness contains interaction frequency, emotional intensity, degree of closeness and reciprocity; exploitative innovation contains learning explicit knowledge, continuous quality improvement, and continuous management improvement; and exploratory innovation includes product design, business model innovation, and development of new markets.

\section{Results and discussion}

This article constructs a logic diagram drawn between cause and effect in accordance with the four-step method (Miles and Huberman 2008). The diagram is utilized to find a logical relationship between the constructs from the evidence, and simplify the paradigm model for summarizing phenomena as the logic line of "conditions - action/interaction - result." The model is used to look for links between numbers of initial categories to ensure the internal validity of the study. We form basic propositions on the basis of an independent analysis of each case,. Adding in other cases forms more-reliable theoretical concepts and causality. Theories, data, and literature were continually analyzed in order to improve the findings, establish contact with existing theories, and delineate the contribution of this paper. After the statement on relevant theories, establishing research models, and series of propositions, this paper analyzes whether the propositions are in line with the case studies examined in order to ensure the reliability of the study.

\section{Analysis of case $\mathrm{H}$}

In $2001 \mathrm{H}$ 's first cousin brought his female first cousin abroad; at the end of the year she helped $\mathrm{H}$ apply to travel to Italy. Over the next two years $\mathrm{H}$ brought his younger brother and sister to Italy. "My younger brother and brother in law used to make sofas in China as well. When they first came, they did not understand the language. I understand Italian, so we cooperated. I dealt with the market, specifically dealing with the Italians. Later my younger brother and his wife also came here. They did not make sofas at home and came here to study." Learning from each other helped these relatives quickly master the explicit operational knowledge, and overcome the "new entrants' disadvantage": "After we all got here, the siblings separately engaged in making timber frames, cushions, sofa covers, and sofas, but in cooperation with each other." Family members worked closely in the business and formed a clear vertical division of labor, reducing communication and opportunity costs in the business chain and improving operational efficiency. In $2006 \mathrm{H}$ and his sister cofounded a sofa factory. The embedded relationship between family members promoted the rapid sharing of industry expertise and market information, helping $\mathrm{H}$ to gain a comprehensive grasp of manufacturing 
technology of products. Expansion of expertise helped $\mathrm{H}$ to become not just someone who knew the language but an enterprise owner as well. He not only mastered the complete sofa production process, but was also able to respond freely to controlling costs and opening up new marketing channels. Strong links between family members provide emotional support and improve the ability to obtain social influence and tacit knowledge. Through the exchange of long-term, high-frequency communication among family members, they also formed an agreed-on code of conduct (Dhanaraj et al. 2004).

Based on the above chain of evidence, we propose:

Hypothesis 1.1: In the start-up phase, strong individual ties in the cluster network can effectively promote exploitative innovation.

After $\mathrm{H}$ opened the sofa factory in 2006, he felt the changes in the economic environment and the labor supply. "Before 2007, we made couches in batches, and now it's this one set and that one set, each set of models only needs two copies, and the demand for an entire batch is small. Some workers are also tired. Making sofas is tiresome and it doesn't bring a lot of money. Some workers moved to other jobs; they do not do it if they do not have to. Next, various departments have stricter inspections on workers, taxes, and managing product varieties. If the layout of the factory, hygiene, or equipment does not meet the requirements, it will be closed." The changing competitive environment prompted $\mathrm{H}$ to use his language advantage to form a more stable relationship of mutual trust with the police, landlords, and contracted factories. "We are very familiar with the police. The police sometimes give us a heads-up before they come, to allow us to be careful. If we can prevent problems in advance we can save a lot on fines. ... The landlord trusts me. The downstairs costs 3,000 EUR and the upstairs costs over 1,000 EUR per month. I came forward and now it is not as expensive, only 800 EUR per month. ... In the past when business was good, the silly foreigners, you claim how much materials are needed and they give you that quantity. Now they all know how much material a set of sofa needs. Before the price was already low, not making any money. Now it only works if it's a cost-effective price. If you have a way of going to the company to talk with the boss, telling the boss the price really does not cover it. You have to give a little more to me. If you do not have other competitors the boss may accept." Establishing trust between related special interest groups like this helps $\mathrm{H}$ to focus on the details of the management process improvement, through strict cost control and control of raw materials to improve the quality and reduce costs. "Workers are paid by the piece. Sewing and carpentry are needed to produce a sofa. Wages have a market price. We are very clear about that so as to control the time and costs. Raw materials are under our own management" in order to respond to diverse customer needs. Through close cooperation with the relevant local authorities and individuals in Prato, and by making full use of the advantages of language and communication $\mathrm{H}$ is able to improve management efficiency in the sofa factory, and is able to respond effectively to the multibrand, small-batch production mode, controlling costs while achieving continuous quality improvement. Development innovation ability has been greatly improved. The factory also received offers from Prato's two largest sofa factories to provide foundry services. However, with the gradual increase in production scale as well as the course of business, there have been some disagreements within the 
family. "We hired more people, recruited more people, then the job is not interesting to do anymore. In 2010 our partnership fell apart. Each person operates their own business exclusively and earns their own money." (All interviews above were conducted with $\mathrm{H}$ on April 19, 2014, Prato). Due to the inherent values regarding family and "face" in Wenzhou, $\mathrm{H}$ was not willing to comment on the current relationship between his brothers and sisters. Strong ties bringing resources also increased the entrepreneur's commitment to members of the network. The network may be too steady and thus limits innovative decisions; overconfidence may inhibit entrepreneurial enthusiasm, or commitment to developing into a certain stage could be a barrier to sustained innovation.

Based on the above chain of evidence, we propose:

Hypothesis 1.2: When entering the sustaining phase and with changes in the competitive environment, the embeddedness of entrepreneurs in the cluster network in the local culture can effectively promote the development of innovation, and excessive relational embeddedness may inhibit innovative decisions.

\section{Analysis of case ZR}

ZR arrived in Italy in 1986, and has engaged in catering, bags, and other industries. He acquired basic Italian fluency when waiting tables. In subsequent years he brought his mother and siblings to Italy. In 1993, influenced by his brother-in-law, he came to Prato and went into the clothing business. "I had a state of mind of fear. I had never seen the clothes, and I could only constantly ask and constantly learn." Fortunately many of ZR's classmates and relatives were already in Prato. Coupled with ZR's own efforts to learn, the garment factory achieved resounding success in one year. Recalling his original intention to go abroad, ZR stated, "My family had difficulties, then I wanted to go abroad to change the living conditions for my family. When I first came I was really frustrated, and felt like crying a lot. But no matter how hard it was I was very happy. ... When I was in Prato, very few people understood the language. Sometimes my relatives and fellows got sick or needed to give birth; we went to the hospital and they did not understand anything. No matter how tired I was, I went to the hospital with them. The hospital staff all knew me." A strong sense of responsibility and commitment to family became ZR's motivation to continuously learn and constantly create value for twenty years. His reputation among his peers also helped ZR acquire critical information in many industries. ZR "started everything from a mere factory worker, learned to use the line trimmer, the double cylinder machine, thanks to his own efforts to learn." With the dedication and talent, ZR soon learned clothing techniques and industry terminology and rapidly became able to work independently. "I love to learn more than others, always willing to learn. When I was working in Milan, I learned all the basic terminology from different restaurants; later when I opened up the garment factory I slowly learned the terminology in clothing also. If I want to settle down here, I at least need to speak some simple Italian. I used the restaurant experience to communicate with foreigners, and received a good client." In addition, ZR also stated," I hold the bar high for all employees; that's why foreigners like to work with us. The company's decoration is also completely different than others. Standardized decoration, good management practices-only by keeping up with these will foreigners trust us." His advantage in language makes it easier for ZR to build trust with Italian customers. 
Continuous improvement of daily management helped his factory expand rapidly. ZR gained recognition outside of his network community due to continuous learning of existing industry knowledge; his strong sense of responsibility stems from strong ties outside of the network that promoted rapid trust building.

Based on the above chain of evidence, we propose:

Hypothesis 2.1: In the start-up phase, strong ties within the cluster network can effectively promote the development of innovation, and culture embeddedness in the local region can help individuals quickly access critical information outside of the cluster network and gain benefits.

Changes in the environment lead to significant changes in cooperative behavior and innovation efficiency of cluster enterprises, encouraging actors to explore new patterns of behavior and norms. With the growing clothing business, a number of changes in the relational embeddedness within the cluster network occurred. On the one hand, ZR was more emotionally attached to his family members: "I cherish my family, my children, my brother, and my brother's children, they are my life." On the other hand, ZR increasingly alienated external members: "Now I really don't want to think about anything else. I just want to do my own things every day. I do not drink or play poker. My hobby is hiking whenever I get a chance, planting flowers; people say my life is very boring. I like the simple life; I do not want my life and communications with people to be complicated. I am also very low-key. I do not want to go out. My brother knows the embassy officials in Rome and Milan very well, but they do not know me at all. My brother says that everything with me is good, only I'm too low-key. Never want to go out there. More than ten years ago the former Chamber of Commerce invited me to attend the Chamber of Commerce many times, and I refused. My classmates say that I do not give them face, do not eat, or go out to play. I just do not want to be social with people. I do better than others, have more money and I never ask people how to do things; I just follow my own principles for management." However, ZR is concerned about the current changes facing the market: "The affluent market in China means that domestic workers do not return once they go back home. In Prato recruitment is more difficult. In a few more years we will just have to shut down the company because people will not have factories or workers".

ZR now increasingly seeks external support from a network of Italian partners in whom he has full confidence and in-depth, open communication. This helped ZR fully integrate into the local regional clusters and culture. ZR established a good working relationship with Italian suppliers: "Although all fabrics are made in China, we still purchase them from foreign suppliers. We do not ask foreigners where they purchased them. Chinese people really have cheaper clothes, but the quality is also worse." ZR appreciates the work attitude of Italian employees, giving core staff full authorization, fully absorbing the views of Italian staff on key issues, and making joint decisions: "I hired four foreigners-an accountant, a designer, a model, and a receptionist for clients. The designer and model were chosen from Italian professional trained people. Foreigners view the job as dearer than their life; Chinese people do not. When working time ends, they go back home, play on WeChat. If I now have to start another business, I will hire only foreigners. Chinese people now play with their phones when working; 
foreigners take work more seriously. I gave a copy of the keys and other important things, including the remote control and alarm, to the Italian designer. I feel very reassured, without any concern. All cash is in the hands of the foreign accountant; every day I just look at the cash inflow and outflow reports. I also look for him when I need to use money. Sometimes when the clothing prototype is out, I just discuss with the designer whether these model products need to reach 30 percent of profits or perhaps 35 percent, maybe 25 percent".

With professional help from Italians, ZR's clothing business has achieved deeper insights and creativity. ZR began designing styles according to customer demands: "The designer and I first consider the needs of customers, combined with my own feelings, and the designer quickly draws style drafts. We choose the style according to customer demand, quickly design, plate, cut on the computer, and then choose the right fabric sample to make a model. The foreigner, in accordance with Italian specifications, draws on the computer. It's faster than we Chinese people. He can draw a dozen drawings a day. He also adjusts design and our models of procurement according to the fabric sample. In this way the design is a better aesthetic fit with Italian and European customers." In addition, ZR created a unique style for his brand: "Our suppliers, the company decoration, clothing style must all comply with the customer's taste, and every piece of clothing has its cultural heritage. The shirt brand is basically my own design. My vision might not be the same as others. If such models based on my design do not have taste, without a certain feeling, I immediately throw them away, and redo. If it feels very good then it's OK. Things that feel good also sell well. The business is slowly getting better".

$\mathrm{ZR}$ also has experience and lessons regarding the development of market sales channels: "This industry is very complex, when summer has not yet begun, you need to immediately plan the second half of the year. It really drains your energy. We are now doing next year's (2015) large customer orders; the second half of this year we have to add some individual orders. My clients are all foreigners, from Europe and Asia." In addition to mastering the professional language, ZR now uses the language as a tool to take the initiative in negotiations: "For example, I sit here with foreign clients; although I understood our clients obviously I will pretend to not understand them. It's good that I'll get a chance to regret." (The above quotations are all from interviews with ZR conducted on April 19, 2014, Prato). ZR relied on social integration with the Italian culture to establish a bond of trust with Italian partners, reduce opportunistic behaviors, and enhance sensitivity to external information (James 2003). The symbiotic and equal relationship between partners outside of the network led to the acquisition of tacit knowledge, forming a unique brand and completing the design of new products and new markets. The integration and reformation of tacit and explicit knowledge ensured the smooth realization of new ideas and innovation.

Based on the above chain of evidence, we propose:

Hypothesis 2.2: During the sustained entrepreneurship phase, with the change of the competitive environment, the same time entrepreneurs reduce the extent of relational embeddedness within network, they increase the degree of cultural embeddedness in the local region, in order to effectively deal with dynamic changes in the competitive environment and to promote the exploratory innovation. 


\section{Analysis of case $X$}

$\mathrm{X}$ has been in Italy for ten years. She has no relatives in Italy, and made use of her husband's family network after marrying to found her own business. She engages in the import and export trade and wholesale footwear. For the entrepreneurial process, $\mathrm{X}$ recalled, "the marriage gifts were more than 10,000 EUR in cash, because a lot of my husband's friends are from Li Ao (a town in Wenzhou). They earn a lot. Most people start their businesses by relying on the cash received at marriage. They quickly married, and then added in their savings and started their business." The support of friends and relatives played a key role in the early days: "From 2004 to 2009 my husband and I had no residency rights. If I saw the police, I fled every time. The companies we opened were under other people's names. We made an agreement on how much money to pay them, and when there were things we needed we would let them come." After the amnesty in 2009, X began to legitimately conduct her business. However, X's business contacts within the family are limited to working together to compete against foreign competitors: "If other people have to get involved, we will unite as a family through large-scale purchases and developing a uniform price to crowd them out." In addition, "The purchase of goods was done on our own. My husband's sister did not give us guidance. We all purchased from the same place and there was a competitive relationship; we all went around Rome to find our own products. We could not all buy the same goods. It's not good for sisters and brothers. If she bought this brand, we had to get other brands to separate the customers. ... I have always run my own separate business. There is no partnership with brothers and sisters. At the beginning my husband's sister said, you do not understand Italian, you do not understand anything, and above all you have never not done business, so partnership is the way to do it. My husband and I had the money and we saw this store was cheap. We did not want a partnership. With a partnership there will certainly be no profit because profits have been accounted for to purchase the goods, and we cannot make money." X believed she had entered the market too late. If she continued with the previous business model and partnered with family members, it would be difficult to have independent careers. Quickly learning the language and engaging in practical exploration of the market became X's tools for entrepreneurial success: "I learned the language. I felt I could learn Italian on my own, and Italian is also very easy to learn. When I was in France I was using headphones to listen to French during work, and every night I stayed up to recite articles. I studied for one month and could speak the language. There is still some trouble with difficult things, but then I slowly get used to them." With the language advantage, $\mathrm{X}$ established close contact with Italian customers. "Italian people are very smart. They are very sensitive to fashion." Communication with Italian customers helped X gain a deeper understanding of fashion. X's judgment on family relationships promoted her awareness of establishing relationships with local customers to expand her business, the only viable strategy for independently expanding the business. While enhancing business execution, it also establishes a wide range of alliances.

Based on the above chain of evidence, we propose:

Hypothesis 3.1: The financial support received from an individual's social network during the start-up phase plays an important role in the success of entrepreneurship. A language advantage can help individuals overcome information and learning 
bottlenecks due to weak ties in the network. Cultural embeddedness can make up for barriers to explicit knowledge transfer during the start-up phase arising from a lack of relational embeddedness.

$\mathrm{X}$ believes that Wenzhou people work much faster than Italians, and are more inclined to recruit workers from Wenzhou. "In 2005 and 2006, I asked friends inside the mall, basically I hired people through relationships. Finding out who was out looking for jobs was a good trick. It is now difficult to recruit. Young people are rare. Sometimes I had to ask the Christian church to help with recruitment." Moreover, $\mathrm{X}$ also finds grasping fashion trends is increasingly important. "Because Italy is the Mediterranean climate, summer is long. Making boots basically means losing business. Even one pair of boots can create great loss. Costs rise year after year." The changing competitive environment prompted X to instigate a series of reforms in custom shoe making. In general, the footwear business first buys a shoe sample and then duplicates it. Exchanges between X and Italian customers helped her understand the potential of more fashionable elements, and she formed a unique aesthetic taste: "After getting a sample, I make changes to the color or material. It is then easy to sell these models. Although the domestic Guangzhou producers have requirements for quantity, if my thoughts on the shoe are good and even if the order is a small quantity, they still help me make them. I can also find a better manufacturer." (All the above interviews were conducted with $\mathrm{X}$ on August 25, 2013, Wenzhou).

Advantages in language and close interaction with Italian customers helped $\mathrm{X}$ to reintegrate knowledge and conduct specific improvements. This contributed to the differentiation of the appearance of the shoes, avoiding the homogenization of competition and making X's trade maintain stable growth. The uncertainty of expected performance brought about by changes in the environment encouraged $X$ to take the initiative and adjust the content and sharing of cultural embeddedness. Cultural embeddedness enhanced the openness of the regional network and promoted new ideas and behaviors to achieve rapid transformation.

Based on the above chain of evidence, we propose:

Hypothesis 3.2: During the sustained entrepreneurship phase, cultural embeddedness in the local area can help entrepreneurs quickly grasp changing market demands in a dynamic environment, continue to improve products, and obtain advantageous exploitative innovation.

\section{Analysis of case $\mathrm{ZY}$}

In $1988 \mathrm{ZY}$ immigrated to Italy with his brother and his mother. Because ZY's father had migrated and successfully started his business in the 1980s, ZY successfully completed his studies in Italy and mastered fluent Italian. ZY's own entrepreneurial path began with working in the family's own factory. His status as a member of "the second Wenzhou generation" encouraged ZY to consider innovations in the business model and products to allow the family business to achieve sustainable development. Starting with a general leather processing business, ZY's business has become an OEM partner with Chanel, Bulgari, and other international brands. In order to expand the company's business as well as to be better accepted by the local people, the company began 
cooperating with Italian businesses beginning in 1996: "We started from a relatively low-end brand OEM, then the Italians took it up for a while. Later, because of our strength in terms of quality and delivery time, we gradually won the trust of clients, and gradually became the secondary agent's source of product." ZY stated that the Italians working with the company gave him a lot of room for development and different platforms, providing even more valuable information than that offered by family members. Because of this information, his business got the opportunity to work directly with the top Italian brands and become the top luggage agent. "The Chinese people from the Italian brand have very high standards. They first look at the style, and then gradually gave us some of the goods to make so that they could look at the quality, look at the speed and look at the price. Once the partnership is established, they start with the simplest products and a small quantity, and then gradually increase the amount and put forward higher requirements. At the same time, you must use German or Japanese machines like JUKI; other production machines in the factory need to be upgraded every year, as well as factory management. In 2007 we moved into the new plant, and started an increasingly close cooperation with the brands. We were the only factory in Florence directly cooperating with the brands." In order to ensure quality, the brand sent representatives directly to the company's production site for inspection and monitoring. One inspector is responsible for maintaining the brand's safety. They go to companies to check whether there is black market labor; the hygiene, health, and mental state of the workers; the degree of cleanliness in the workshop; and whether there are violations of intellectual property rights. Another type of monitoring checks the quality and process. "They check the quality of the production process, and communicate directly with the company's Italian management. They propose quality improvement requirements to ensure brand quality." By working closely with the Italian brands, the company's product quality has been continuously improving. Through continuous equipment upgrades, the company gained production techniques compatible with other brands' OEM. In order to allow the company to better reflect regional characteristics, "we hired eleven Italian employees who are responsible for quality, financial, and administrative work. They are mostly professionals. We also hired a Chinese woman as a translator who is responsible for informing the workers of what the Italians mean, primarily the content related to technological requirements and quality requirements." Through continuous improvement of management processes, the company established confidence in the quality of the products and formed consistent business rules and social norms between the company and its partners. This special trust and cooperation between the Italian partners, brands, and Italian staff and entrepreneurs promoted rapid embeddedness in the local culture; cultural embeddedness became the internal driving force for enhancing quality and improving management.

Based on the above chain of evidence, we propose:

Hypothesis 4.1: During the start-up phase, cultural embeddedness promotes continuous improvement in quality and management, enhancing exploratory innovation.

In $2005 \mathrm{ZY}$ gradually began to participate in Italian politics, culture, and social interactions, and has established close ties with the Italian Embassy and the local government. Through his long period of living abroad as well as his interest in 
wine, ZY learned the status of Italian wine in the world of wine aficionados. He also saw the gap in the Italian wine market in China: "China's wine market is slowly rising, especially in high-quality Italian wines, good quality, but compared to French wines, the promotion efforts are not enough." (All the above interviews were conducted with ZY on March 18, 2014, Florence). In 2006 ZY began working as an agent for a midrange wine brand. In early $2009 \mathrm{ZY}$ performed a detailed market research on China's overall wine market. He used his own foundry store's relationship to establish a top Italian wine brand, acquired a winery in Italy, and used direct sales from the winery to import it to China. In $2010 \mathrm{ZY}$ established a wine company in Shanghai, and has invited Italian consulate personnel and business contacts to participate in wine tasting and other promotional activities there. Using the special trust established within the Italian political and business world, ZY captured new business opportunities. With his reputation for access to top luggage brands and OEM experience, he rapidly implemented this diversification strategy and successfully expanded the wine market. He has become China's largest distributor of high-end Italian wine.

Based on the above chain of evidence, we propose:

Hypothesis 4.2: During the sustained entrepreneurship phase, deep cultural embeddedness with the local region can help entrepreneurs implement brand strategy, develop new projects, and promote expansion into new markets, which are conducive to exploratory innovation.

\section{Summary}

In the above four cases, we captured the various characteristics that migrant entrepreneurship presents during the start-up and sustained-entrepreneurship phases. In the early days economic policy was relatively loose, with an abundant labor force, and faced mass production demands. When entering the sustained entrepreneurship phase, economic policy became increasingly tight, with an increasingly tight labor supply, and customer demands were more varied but in smaller quantity. Increasing competitiveness and a changing external environment jointly promote immigrant enterprises to achieve a transition from the start-up phase to the sustained entrepreneurship phase. The multiple case studies and propositional logic replication lead to Hypotheses 5 and 6.

Hypothesis 5: During the start-up phase, relational embeddedness is conducive to exploitative innovation, and cultural embeddedness helps compensate for insufficient information that brings obstacles and bottlenecks.

Hypothesis 6: During the sustained entrepreneurship phase, relational embeddedness is not conducive to exploitative innovation, and cultural embeddedness contributes to the realization of ambidextrous innovation.

\section{Conclusions}

\section{Primary findings}

"One Belt and One Road" is the implementation of China's national strategy to go abroad. Through initial entrepreneurship and sustained entrepreneurship migrants, especially overseas migrant entrepreneurs from Wenzhou, built networks of entrepreneurs 
and industrial clusters overseas, and have accumulated valuable experience in ambidextrous innovation. This serves as a good reference. Through building cluster networks, Wenzhou migrants, as members of the nonelite group, gained motivation and resources for sustained entrepreneurship. With meticulous division of labor and full exploitation of social capital, they reduced the barriers to new entrants during the start-up phase. However, after they succeeded in starting up a business, relational embeddedness intensified the formation of a closed network. Faced with upheavals in entrepreneurial environment, economic policy and labor factor dramatically change the mode of production; immigrant enterprises from Wenzhou are confronted with development imprisonment. This study focuses on the core issue of how immigrant entrepreneurs embedded in cluster networks interact and integrate with the regional Italian culture at different stages of entrepreneurship to improve their sustained entrepreneurship. Through longitudinal multicase analysis, we confirmed that changes in the external environment have an important impact on the embeddedness of Wenzhou immigrant businesses. Interaction between immigrant corporations and the regional culture can not only achieve integration, but can also promote ambidextrous innovation. The relational embeddedness of Wenzhou immigrant businesses in cluster networks and cultural embeddedness in the regional economy change as the entrepreneurship phase changes and produces different forms of coupling.

This paper produced three main findings.

First, the entrepreneurial process and innovation behavior of Wenzhou migrants are characterized by distinct phases, from the early start-up phase that focuses on exploratory innovation to the sustained entrepreneurship phase in which ambidextrous innovation evolves. Different innovation behavior forms different path dependence on different resources. There are also different combinations of resources. In the early days of entrepreneurship embeddedness is mainly composed of strong ties. It achieves lowcost venture copying by using observation and imitation. Strong ties promote exploitative innovation. Cultural embeddedness in this stage of development can also play a role in promoting innovation. There are two possible paths. First, cultural embeddedness is manifested in language advantages, helping immigrants to access critical information outside of the network and obtain benefits. Second, language advantages can also help companies to overcome information isolation and learning bottlenecks due to weak ties. Cultural embeddedness can make up for the lack of relational embeddedness that causes barriers in the transmission of explicit knowledge. Both paths can lead to the coupling of embedding and cooperative relations in culture, promoting exploitative innovation in the early stages and also contributing to the evolving cluster network of Wenzhou immigrants. With changes in the competitive environment, the enterprises of Wenzhou immigrants consciously reduce the degree of relational embeddedness to better implement exploitative innovation. However, only reducing the degree of relational embeddedness is not conducive to achieving ambidextrous innovation, and cultural embeddedness can help companies acquire the integration advantages of exploratory innovation and exploitative innovation. This is essential not only for ongoing product upgrades and quality improvement, but also for the development of new products and markets. Therefore sustained entrepreneurship needs to maintain relational embeddedness in the network at an appropriate level, and gradually increase the level of cultural embeddedness. 
Second, the first and second generations of Wenzhou migrants in Italy differ in their implementation paths of entrepreneurship. Timing also has an impact on the innovative path. Entrepreneurs $\mathrm{H}$ and ZR immigrated to Italy long ago; their network based on kinship and geographical closeness built a platform for sharing resources. The initial entrepreneurial path is very dependent on cooperation among family members, and information exchange between relatives and fellows. The low-cost imitation business model becomes the most direct and effective developmental path. $\mathrm{H}$ had limited experience in starting a business; she had to rely on her husband's family network to successfully enter the footwear business. Family networks helped them cope with potential market risks. However, strong ties come with decision-making commitments to family members, which curb the innovative behavior of individuals. Therefore ZR achieved greater business success and development by relying on cultural embeddedness. ZY belongs to the second generation of entrepreneurs, and had to inherit and develop the family business. Homogeneous and redundant information in a closed network cannot provide new sources of profit. He relied on heterogeneous information and innovative resources outside of the network to capture business opportunities in a timely fashion, successfully cracking the industrial lock through integration of resources and breaking rigid decision-making processes caused by values.

Third, this study found that strong ties during the start-up phase can contribute to exploitative innovation, which is in consensus with the conclusions of other research. The most significant contribution of this paper is its clear revelation of the mechanism behind the impact of cultural embeddedness on ambidextrous innovation at different stages. Cultural embeddedness in early stages promotes exploratory innovation; to achieve sustained entrepreneurship the role of cultural embeddedness in exploitative innovation needs to be utilized. Based on immigration networks and immigration chain theory, the expanding number of Italian immigrants from Wenzhou will significantly reduce their risks and difficulties in starting a business in Italy in the future. Despite the financial crisis and high unemployment problems faced by European countries, the number of new businesses established in Italy by immigrants is still increasing. Data shows that from 2012 to 2013 the number of Chinese enterprises in Italy increased by 3.1 percent. Although the overall number of Italian companies decreased by 1.6 percent, the number of Chinese enterprises in Italy increased by 6.1 percent, of which about 70 percent are run by Wenzhou immigrants. As entrepreneur X observed, "in the past, business was just like our struggle in Shanghai; hardship and luck are what it takes and now it relies on relationships. Whether the family is strong or not, new companies with no foundation will certainly be eliminated." Enterprises in the cluster compete fiercely. New entrants must open up new markets, establish more-flexible business alliances, and understand the connotations of cultural embeddedness in order to achieve sustained entrepreneurship.

\section{Theoretical contributions and practical implications}

Efficient allocation of resources as well as in-depth market integration make up the important cornerstone in creating a community with shared interests that embodies economic integration and cultural tolerance. The theoretical and practical contributions of this paper are in the following three aspects. First, the paper breaks previous limitations of investigating only one dimension of ambidextrous innovation. It proceeds from the 
implementation mechanism of migrants' sustained entrepreneurial process, taking into account the evolution of the cluster network, and explores the unique pattern of the collaborative development of cultural embeddedness and relational embeddedness. This study enriches the understanding of evolutionary law of overseas cluster networks, and refines the rational elements that promote the orderly evolution of advanced cluster networks. Second, this paper looks at the functional mechanisms of relational and cultural embeddedness from the perspective of their coupling, explaining the evolution of self-organizing networks in depth, and strengthening the theory of ambidextrous innovation and embeddedness. Third, this paper describes how at different stages of entrepreneurship relational and cultural embeddedness coordinate to create a replicable sustained entrepreneurship. This will encourage new immigrant entrepreneurs to develop appropriate and innovative business strategies, as well as offering a strategic reference for successful companies in terms of sustainable development.

\section{Future research directions}

Because of the limitations of case studies, this paper cannot cover all the embedded paths in the entrepreneurial process of overseas Wenzhou migrants. Future research should consider analysis of different industries and sizes of samples to test the findings of this study on a large scale in order to obtain a more-general conclusion. In addition, future research could also be carried out in depth in the following aspects. First, in the face of different environments, different industries, and different intensity of competition, the degree of various embedded relationships differs. The effective threshold range also changes as the above conditions evolve. Subdivision of the role of various embedded scenarios will become an important method for enhancing the external validity of these case studies. Second, the network of oversea Wenzhou migrants lacks an intermediary service structure that specializes in coordinating and organizing. Structural holes are too scarce, which restricts the self-organizing evolution of social networks and prevent them from forming a resilient, scalable economic system. Research into the core enterprise of the network can reveal the core business strategy that affects the entire network's ambidextrous innovation. Finally, case studies are helpful in finding the evolution of the relationship between the selection of the ambidextrous innovation mode and embedded paths. Future research can use the simulation method to simulate the evolution of overseas networks and explore the pattern of innovative cluster networks.

It should be noted that during the process of sustained entrepreneurship, successful pioneers provided a wealth of qualitative research data for this study, but behind them are countless of quiet people who failed but made difficult explorations and accumulated rational experiences. Reflections on stories of failure can better provide us with profound insights into the emotional choices and rational judgments of immigrant entrepreneurs. During the interviews the authors found that most overseas Chinese businesspeople in Italy, including those from Wenzhou, have experienced many failures in choosing between different industries and had moved between different cities. Their current success is derived from their inherent entrepreneurship, but is also rooted in the continuing pursuit of business values. Reflections on failed experiences become valuable assets in their success. Successful experiences are certainly valuable, but experiences of failure are indispensable. In view of this, follow-up studies are needed to 
further investigate the typical cases of failed entrepreneurship or cases of continuous transformation in the entrepreneurial process in order to provide a more-vivid and comprehensive portrait of the true paths of entrepreneurship and integration of migrants abroad.

\section{Competing interests}

The authors declare that they have no competing interests.

\section{Authors' contributions}

YZ collected data and drafted the manuscript. MZ conducted qualitative analysis. Both authors read and approved the final manuscript.

\section{Acknowledgements}

This research was supported by the Major Project of the National Social Science Foundation "Research on the mechanism of entrepreneurs' expanding cluster network and its effects on regional economic growth" (71273193); "Paternalistic leadership, self-cognitive bias and ambidextrous innovation performance: A view based on psychological distance" (71402124). This research was also supported by the Philosophy Social Science Foundation for Key Research Center of Zhejiang Province "The regional industrial cluster network evolution of overseas Wenzhouness (15JDWZ01YB)"; "The intergenerational entrepreneurship and entrepreneurship remodeling of Wenzhou entrepreneurs" (15JDWZO2YB); and the Philosophy Social Science Foundation for Wenzhou "Ambidextrous innovation and intergenerational entrepreneurship in Wenzhou" (15wsk083).

Received: 26 October 2015 Accepted: 4 December 2015

Published online: 18 January 2016

\section{References}

Baer, Markus. 2010. The strength-of-weak-ties perspective on creativity: a comprehensive examination and extension. Journal of Applied Psychology 95(3):592-601.

Benner, Mary J., and Michael L. Tushman. 2003. Exploitation, exploration, and process management: the productivity dilemma revisited. Academy of management review 28(2):238-256.

Boschma, Ron. 2005. Proximity and innovation: a critical assessment. Regional studies 39(1):61-74.

Chaganti, Radha, and Patricia G. Greene. 2002. Who are ethnic entrepreneurs? A study of entrepreneursapos; ethnic involvement and business characteristics. Journal of Small Business Management 40(2):126-143.

Chen, Yun, and Yuangiong He. 2010. Immigrant entrepreneurship status review and the future (in Chinese). Foreign Economics and Management 8:35-41.

Chen, Yi., and Yili Zhang. 2013. Social capital, social networks and entrepreneurial clusters (in Chinese). Business Economics and Management 10:40-47.

Dhanaraj, Charles, Marjorie A. Lyles, Kevin K. Steensma, et al. 2004. Managing tacit and explicit knowledge transfer in IJVs: the role of relational embeddedness and the impact on performance. Journal of International Business Studies 35(5):428-442.

Eisenhardt, Kathleen M., and Melissa E. Graebner. 2007. Theory building from cases: opportunities and challenges. Academy of management journal 50(1):25-32.

Etemad, Hamid. 2004. International entrepreneurship as a dynamic adaptive system: towards a grounded theory. Journal of international entrepreneurship 2(1-2):5-59.

Granovetter, Mark. 1985. Economic action and social structure: the problem of embeddedness. American journal of sociology 91(3):481-510.

Hofstede, Geert, Gert Jan Hofstede, and M. Minkov. 1991. Cultures and organisations: software of the mind: intercultural cooperation and its importance for survival. New York, NY: McGraw-Hill.

Hoy, Frank, and Pramodita Sharma. 2010. Entrepreneurial family firms. New Jersey: Prentice Hall.

Hsu, Jinn-yuh, and AnnaLee Saxenian. 2000. The limits of guanxi capitalism: transnational collaboration between Taiwan and the USA. Environment and Planning 32(11):1991-2006.

Hulsink, Willem, and Tom Elfring. 2008. The locus of innovation in small and medium-sized firms: the importance of social capital and networking in innovative entrepreneurship, Cases in Technological Entrepreneurship: Converting Ideas into Value, 80-106. Cheltenham: Edward Elgar.

James, Alne. 2003. Regional culture, corporate strategy and high tech innovation: Salt Lake City. PhD Dissertation: University of Cambridge.

Ji, Min, Hanhui Hu, and Chen Jindan. 2011. Network morphology upgrade and evolution of endogenous industrial clusters-Based on analysis of Tianfen Qidong power tool industry cluster (in Chinese). Scientific Research 6:861-867.

Lakemond, Nicolette, and Jonas Detterfelt. 2013. Counterbalancing exploitative knowledge search during environmental dynamism: reinforcing new ideas for existing products. Creativity and Innovation Management 22(4):420-434.

Lavie, Dovev, Uriel Stettner, and Michael L. Tushman. 2010. Exploration and exploitation within and across organizations. Academy of Management Annals 4(1):109-155.

$\mathrm{Li}$, Xinchun, Xuan He, and Chen Wenting. 2008. Entrepreneurship and family enterprise strategy of entrepreneurial heritage-A case study on century-old brand Lee Kum Kee (in Chinese). Management World 10:127-140.

Maskell, Peter. 2010. Towards a knowledge-based theory of the geographical cluster. Industrial and corporate change 10(4):921-943.

Miles, and Huberman. 2008. Analysis of qualitative data: Methods and practice, translated by Fenfen Zhang. Chongqing: Chongqing University Press.

Moore, Spencer, Daniel Mark, Gauvin Lise, et al. 2009. Not all social capital is good capital. Health \& place 15(4):1071-1077. 
Ndofor, Hermann, and Richard L. Priem. 2011. Immigrant entrepreneurs, the ethnic enclave strategy, and venture performance. Journal of Management 37(3):790-818.

Perry-Smith, Jill. 2006. Social yet creative: the role of social relationships in facilitating individual creativity. Academy of Management Journal 49:85-101.

Russo, Angeloantonio, and Clodia Vurro. 2010. Cross-boundary ambidexterity: balancing exploration and exploitation in the fuel cell industry. European Management Review 7(1):30-45.

Sarasvathy, Saras D., and Nicholas Dew. 2005. New market creation through transformation. Journal of Evolutionary Economics 15(5):533-565.

Song, Quancheng. 2013. Chinese diaspora in Europe: the size, characteristics, problems and prospects (in Chinese). Journal of theory 11:69-73.

Steier, Lloyd. 2001. Next-generation entrepreneurs and succession: an exploratory study of modes and means of managing social capital. Family Business Review 14(3):259-276.

Tang, Chaoying, and Huiju Zou. 2012. Knowledge network and interpersonal development team based on creativity (in Chinese). Management Review 4:94-100.

Wang, Qingfan. 2012. Ethnic entrepreneurship studies in geography: a review. Geography Compass 6(4):227-240.

Xiang, Yongsheng. 2013. Research on mechanisms of cultural embeddedness, internet behaviors and cluster enterprises innovation-Theoretical framework and propositions (in Chinese). Lanzhou Commercial College Report 6:37-42.

Xu, Huabing. 2012. The regional culture and Wenzhou migrants (in Chinese). Overseas Chinese History Studies 2:44-52.

Yin, Robert K. 2008. Case study research: design and methods, 2nd ed. Thousand Oaks, Calif: Sage.

Zhang, Yili, Chen Yi, and Ni. Jing. 2012. Networks and clusters: mechanism of the group formation of Wenzhou entrepreneurs (in Chinese). Zhejiang Social Sciences 1:118-124.

Zhou, Huanhuai, and Pei Zhu. 2014. Why non-elite groups, can succeed in business abroad? Based on an empirical study on Florence's Wenzhou businessmen (in Chinese). Management World 2:68-76.

Submit your manuscript to a SpringerOpen ${ }^{\circ}$ journal and benefit from:

- Convenient online submission

- Rigorous peer review

- Immediate publication on acceptance

- Open access: articles freely available online

- High visibility within the field

Retaining the copyright to your article

Submit your next manuscript at $\boldsymbol{\nabla}$ springeropen.com 